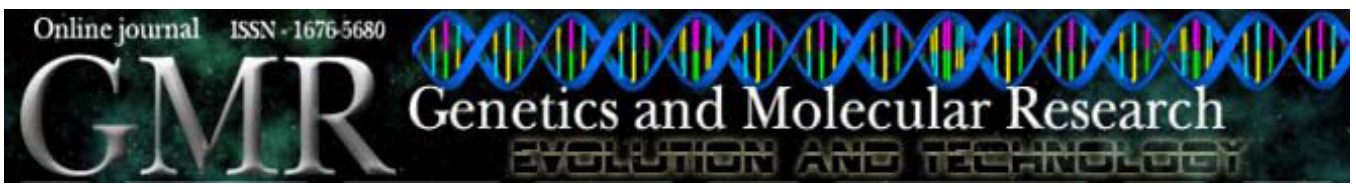

Short Communication

\title{
Genetic variability of Mahanarva sp (Hemiptera: Cercopidae) collected from different sites in Brazil
}

\author{
A.M. Auad ${ }^{1}$, R. Domingues ${ }^{1}$, M.A. Machado ${ }^{1}$, L.S. Souza ${ }^{1}$, G.S. Carvalho ${ }^{2}$ \\ and S.V. Paula-Moraes ${ }^{3}$ \\ ${ }^{1}$ Embrapa Gado de Leite, Juiz de Fora, MG, Brasil \\ ${ }^{2}$ Pontifícia Universidade Católica do Rio Grande do Sul, Porto Alegre, RS, Brasil \\ ${ }^{3}$ Embrapa Cerrados, Planaltina, DF, Brasil \\ Corresponding author: A.M. Auad \\ E-mail: amauad@cnpgl.embrapa.br
}

Genet. Mol. Res. 9 (2): 1005-1010 (2010)

Received February 18, 2010

Accepted March 20, 2010

Published June 1, 2010

DOI 10.4238/vol9-2gmr794

\begin{abstract}
Spittlebugs are the leading cause of damage to tall grasses. Annual losses are estimated to reach 2.1 billion dollars in sugarcane crops and grazing land throughout the world. Correct identification of these species is difficult due to similarities in color, body size and male genitalia. Molecular markers have been useful in the identification and assessment of genetic diversity of many species. We investigated the genetic diversity of the spittlebug species Mahanarva fimbriolata, M. spectabilis and M. liturata and looked for markers that could aid in their identification. DNA from 34 spittlebug specimens, collected from six different regions of Brazil (Brasília, Campo Grande, Valença, Presidente Prudente, Juiz de Fora, and Porto Alegre), was analyzed with 29 RAPD primers, generating 501 polymorphic markers. High genetic variability was found among individuals $M$. fimbriolata (0.37), M. spectabilis (0.18) and M. liturata (0.69). Species-specific molecular RAPD markers were identified for each of the three species; these could be used as auxiliary tools for their correct identification.
\end{abstract}

Key words: Molecular marker; RAPD; Spittlebugs 
It is estimated that spittlebugs cause annual losses of up to 2.1 billion dollars to sugarcane crops and grazing land throughout the world. In Brazil, cercopid species in the genus Mahanarva are the leading cause of damage to large grasses such as sugarcane and elephant grass, with the main offenders being Mahanarva fimbriolata (Stal, 1854), M. spectabilis (Distant, 1909) and M. liturata (Le Peletier and Serville, 1825).

It is often hard to identify the species of this genus because the main distinguishing characteristics are coloration and body size (subject to phenotypic plasticity) and morphology of the male genitalia. Molecular markers have been found very useful to identify species as well as to analyze the genetic distance and structure of populations (Castiglioni et al., 2005; Mikac and Clarke, 2006; de Oliveira et al., 2007; Castro et al., 2007). In less-studied species such as Mahanarva, the random amplified polymorphic DNA (RAPD) technique is a valuable molecular tool since it does not require previous DNA sequencing studies and since arbitrary primers are used (Ercan et al., 2004). However, the RAPD technique is sometimes criticized about its alleged lack of reproducibility and repeatability.

Nevertheless, these features can be avoided with improvement of laboratory techniques and scoring system, making RAPD markers highly stable in controlled experimental conditions (Skroch and Nienhuis, 1995; Weising et al., 1995; Parani et al., 1997; Bussell, 1999).

Populations of Mahanarva spectabilis show morphological differences depending on the regions in which they are found in Brazil. This would suggest a genetic isolation although there is little information on inter- and intraspecific genetic variations. The aim of this study was to use molecular markers to assess the genetic diversity of $M$. fimbriolata, M. spectabilis and $M$. liturata and to select specific markers to help in the correct identification of these species.

Specimens of M. spectabilis were captured in Brasília, Campo Grande, Valença, and Presidente Prudente, while individuals of $M$. fimbriolata and $M$. liturata were collected in Juiz de Fora and Porto Alegre (Figure 1). The spittlebugs Deois (Pandysia) schach (Fabricius, 1787) and Notozulia entreriana (Berg, 1879) were included as external groups. The sites were chosen because of the impact different spittlebug species have had on forage grasses.

Adults were collected with an insect net on Brachiaria and elephant grass, sorted and stored in $100 \%$ alcohol. Some of the specimens caught were submitted to taxonomic species identification according to the morphology of the male genitalia.

For the genetic studies, five specimens of $M$. spectabilis and $M$. fimbriolata and three specimens of M. liturata were sampled from each location, along with three specimens of each external control group. The appendages (legs and wings) and head were removed from each insect. DNA was extracted from the remaining insect parts with CTAB according to the protocol of Ferreira and Grattapaglia (1995) with modifications.

A specimen from each group was used in the amplification test with decamer primers to select the best ones, based on the sharpness and repeatability of the reaction. Of the 40 primers tested (obtained from Operon Technologies Inc.), 29 were finally used for amplification of all the individuals.

Polymerase chain reaction cycling parameters consisted of an initial temperature of $94^{\circ} \mathrm{C}$ for $5 \mathrm{~min}$, followed by 45 cycles of $1 \mathrm{~min}$ at $94^{\circ} \mathrm{C}, 1 \mathrm{~min}$ at $36^{\circ} \mathrm{C}$ and $2 \mathrm{~min}$ at $72^{\circ} \mathrm{C}$, and $10 \mathrm{~min}$ at $72^{\circ} \mathrm{C}$ for a final extension (Applied Biosystems 9700 Thermocycler, Foster City, $\mathrm{CA}$, USA). The total volume of each reaction was $25 \mu \mathrm{L}$, containing $10 \mathrm{mM}$ Tris- $\mathrm{HCl}, \mathrm{pH} 8.4$, $50 \mathrm{mM} \mathrm{KCl}, 2.5 \mathrm{mM} \mathrm{MgCl}, 0.1 \%$ Triton X-100, $0.4 \mu \mathrm{M}$ primer, $0.1 \mathrm{mM}$ of each dNTP, $1 \mathrm{U}$ Taq DNA polymerase, and $45 \mathrm{ng}$ genomic DNA. RAPD amplification products were separated on a $2 \%$ agarose gel, stained with ethidium bromide and photographed under UV light. 


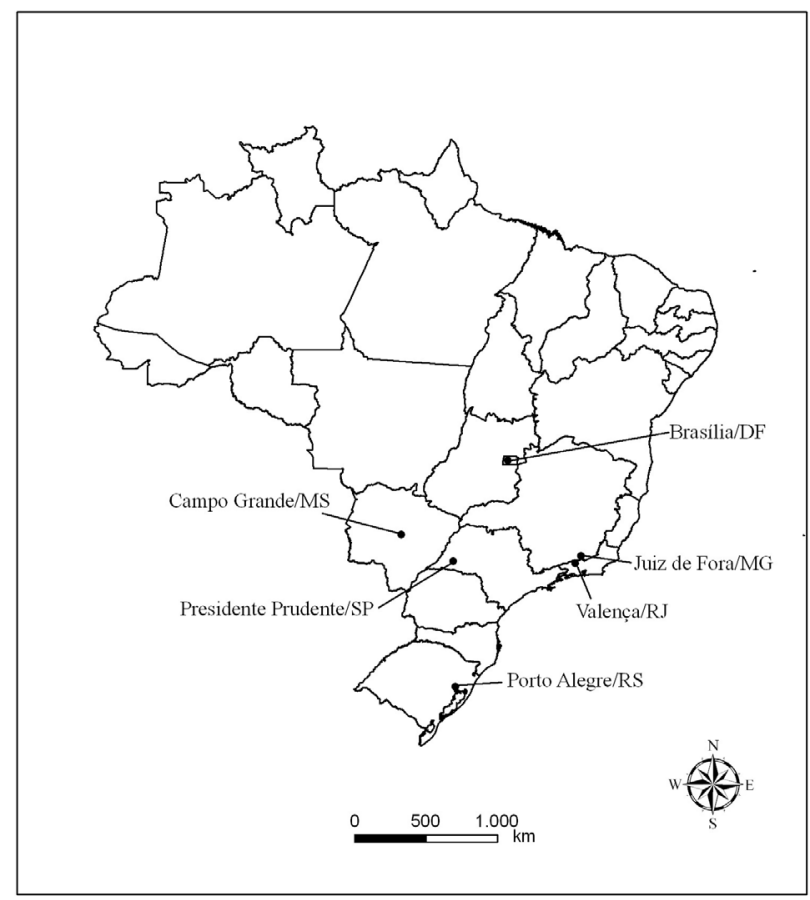

Figure 1. Geographical locations where spittlebugs were sampled in Brazil.

All reactions with selected primers were done in duplicate. Only the highly intense and reproducible fragments were included in the analysis, as recommended by Pérez et al. (1998). A binary matrix was constructed according to the presence (1) or absence (0) of bands among the specimens.

The relative genetic distance between each pair of individuals was estimated using the arithmetic complement of Dice's coefficient (Nei and Li, 1979). Cluster analysis was performed using the unweighted pair group method with arithmetic mean (UPGMA). The arithmetic means of the genetic distances found between all the individuals in question were calculated to analyze the intra- and intergroup mean genetic distances (MGDs).

Gene flow $(\mathrm{Nm})$ between M. spectabilis groups was estimated from the $\Phi$ st component of the $\Phi$ statistic introduced by Excoffier et al. (1992), using the following formula:

$$
\mathrm{Nm}=[(1 / \Phi s t)-1] / 4
$$

This approach does not require previous knowledge of the allele frequencies or making specific assumptions (Excoffier et al., 1992), and thus provides an alternative to the use of dominant markers.

A total of 501 markers were analyzed. All of them were polymorphic among the 34 individuals studied, showing the high genetic variability of the specimens. The MGDs between individuals of $M$. spectabilis ranged from 0.15 to 0.22 within a single location and 0.16 to 0.33 
among different locations, with an intraspecific MGD of 0.18 (Table 1). Among the M. fimbriolata and M. liturata individuals, the MGDs were 0.37 and 0.69 , respectively, showing higher intraspecific variability compared to $M$. spectabilis. Cluster analysis clearly separated these three species, with MGDs of 0.67 between M. spectabilis and M. fimbriolata, 0.87 between $M$. spectabilis and M. liturata and 0.89 between M. fimbriolata and M. liturata (Table 1).

Table 1. Matrix of mean genetic distances (MGDs) among Mahanarva populations.

\begin{tabular}{|c|c|c|c|c|c|c|c|c|}
\hline & M. spectabilis ${ }^{l}$ & M. spectabilis ${ }^{2}$ & M. spectabilis ${ }^{3}$ & M. spectabilis ${ }^{4}$ & M. fimbriolata & M. liturata & $\begin{array}{l}\text { Deois } \\
\text { schach }\end{array}$ & $\begin{array}{l}\text { Notozulia } \\
\text { entreriana }\end{array}$ \\
\hline M. spectabilis ${ }^{l}$ & $0.22(-)$ & - $\quad(0.93)$ & $-\quad(0.32)$ & - $(0.35$ & - & - & - & - \\
\hline M. spectabilis ${ }^{2}$ & $0.27(0.21)$ & $0.2 \quad(-)$ & - $\quad(0.39)$ & - $\quad(0.42)$ & - & - & - & - \\
\hline M. spectabilis $^{3}$ & $0.33(0.44)$ & $0.29(0.39)$ & $0.15(-)$ & - (6.10) & - & - & - & - \\
\hline M. spectabilis ${ }^{4}$ & $0.33(0.42)$ & $0.29(0.37)$ & $0.16(0.04)$ & $0.16(-)$ & - & - & - & - \\
\hline M. fimbriolata & 0.65 & 0.66 & 0.68 & 0.67 & 0.37 & - & - & - \\
\hline M. liturata & 0.88 & 0.87 & 0.87 & 0.87 & 0.89 & 0.69 & - & - \\
\hline Deois schach & 0.95 & 0.93 & 0.93 & 0.94 & 0.93 & 0.94 & 0.43 & - \\
\hline Notozulia entreriana & 0.94 & 0.93 & 0.92 & 0.92 & 0.95 & 0.94 & 0.91 & 0.3 \\
\hline
\end{tabular}

Values of $\Phi$ st generated by AMOVA (lower diagonal) and gene flow index (upper diagonal) are in parentheses. M. spectabilis sampled in the following locations: Valença (1), Campo Grande (2), Brasília (3), and Presidente Prudente (4).

There was similarity between and within populations of M. spectabilis denoting a tendency for clustering individuals from Presidente Prudente and Brasília. The distances between these populations were greater than the distances between populations from Campo Grande and Valença. These findings corroborate the identification done using morphological traits based on the individuals' coloration of the tegmen, head and scutellum. It is important to point out that the samples from Presidente Prudente and Brasília had wings with four color patterns, while the populations from Valença and Campo Grande had wings with only one color pattern. However, the MGD between the populations with greater wing morphological differences was smaller $(0.16)$ than those with a single color pattern wing (0.27), indicating that there is no correlation between genetic distance and the number of morphological differences in the specimens. The absence of a correspondence between morphological and RAPD data has been reported elsewhere in the literature (Semagn, 2002).

Morphological differences between populations of the same species dispersed over latitude and elevation gradients have been reported for various insect groups (Hawkins and Lawton, 1995; Smith et al., 2000) and are generally associated with temperature, humidity and photoperiod conditions (Tauber et al., 1986).

The cluster analysis carried out based on genetic distances showed the genetic separation between the species $M$. fimbriolata, $M$. spectabilis and $M$. liturata, as well as a strong separation from the control group with an MGD of 0.94 .

Six markers were exclusively identified for M. spectabilis individuals. Likewise, eight exclusive markers for $M$. fimbriolata and four exclusive markers for M. liturata (Table 2) were identified. These markers can be used as auxiliary tools in the correct identification of these species, currently carried out by taxonomists using external morphological traits. 
Table 2. Oligonucleotide primers (Operon Technologies), nucleotide sequence, number of distinct fragments analyzed, and the exclusive markers identified for the Mahanarva species and their respective fragment sizes.

\begin{tabular}{|c|c|c|c|c|}
\hline \multirow[t]{2}{*}{ Primer } & \multirow[t]{2}{*}{ Nucleotide sequence } & \multirow[t]{2}{*}{ Fragments analyzed } & \multicolumn{2}{|c|}{ Exclusive marker } \\
\hline & & & Species & Fragment size (bp) \\
\hline OPA-13 & CAGCACCCAC & 16 & M. spectabilis & 575 \\
\hline OPA-16 & AGCCAGCGAA & 10 & M. fimbriolata & 981 \\
\hline OPB-01 & GTTTCGCTCC & 10 & - & - \\
\hline OPB-06 & TGCTCTGCCC & 9 & - & - \\
\hline OPB-07 & GGTGACGCAG & 17 & M. spectabilis & 723 \\
\hline \multirow[t]{2}{*}{ OPB-20 } & GGACCCTTAC & 10 & M. spectabilis & 764 \\
\hline & & & M. fimbriolata & 1595 \\
\hline OPC-13 & AAGCCTCGTC & 12 & M. spectabilis & 888 \\
\hline OPC-18 & TGAGTGGGTG & 17 & M. liturata & 428 \\
\hline OPC-19 & GTTGCCAGCC & 22 & - & - \\
\hline OPD-08 & GTGTGCCCCA & 15 & M. liturata & 303 \\
\hline OPE-04 & GTGACATGCC & 18 & M. fimbriolata & 313 \\
\hline OPE-11 & GAGTCTCAGG & 15 & - & - \\
\hline OPE-18 & GGACTGCAGA & 13 & M. liturata & 392,183 \\
\hline OPF-01 & ACGGATCCTG & 15 & - & - \\
\hline OPF-06 & GGGAATTCGG & 10 & - & - \\
\hline OPF-09 & CCAAGCTTCC & 11 & M. spectabilis & 667 \\
\hline OPF-10 & GGAAGCTTGG & 24 & - & - \\
\hline OPG-08 & TCACGTCCAC & 16 & M. fimbriolata & 420 \\
\hline OPG-10 & AGGGCCGTCT & 22 & - & - \\
\hline OPG-11 & TGCCCGTCGT & 15 & - & - \\
\hline OPG-17 & ACGACCGACA & 26 & M. fimbriolata & 642 \\
\hline OPG-18 & GGCTCATGTG & 8 & M. fimbriolata & 738 \\
\hline OPH-03 & AGACGTCCAC & 19 & - & - \\
\hline OPH-05 & AGTCGTCCCC & 26 & - & - \\
\hline OPH-08 & GAAACACCCC & 35 & - & - \\
\hline \multirow[t]{2}{*}{ OPH-12 } & ACGCGCATGT & 39 & M. spectabilis & 480 \\
\hline & & & M. fimbriolata & 762 \\
\hline OPH-19 & CTGACCAGCC & 22 & - & - \\
\hline OPI-04 & CCGCCTAGTC & 10 & M. fimbriolata & 401 \\
\hline OPJ-04 & CCGAACACGG & 19 & - & - \\
\hline
\end{tabular}

An exclusive marker was also found for the individuals of $M$. spectabilis collected in Presidente Prudente and Brasília (primer OPH-08, 757-bp marker). Oliveira et al. (2004), using RAPD markers to distinguish subspecies of Tetragonisca angustula Latreille, found specific bands for each subspecies. Waldschmidt et al. (2000) also identified RAPD markers present in one subspecies of Melipona and absent in another.

Among the M. spectabilis populations, the fixation index ranged from 0.04 to 0.44 , and the estimated gene flow index ranged from 0.32 to 6.10 . The lowest fixation indices and highest flow indices were found between the populations from Presidente Prudente and Brasília (Table 1). These findings indicate the possible existence of subspeciation within the species. However, a more informative sampling will be necessary to confirm this conjecture.

\section{ACKNOWLEDGMENTS}

Research supported by Fundação de Amparo à Pesquisa do Estado de Minas Gerais (FAPEMIG) and Conselho Nacional de Pesquisa (CNPq). 


\section{REFERENCES}

Bussell JD (1999). The distribution of random amplified polymorphic DNA (RAPD) diversity amongst populations of Isotoma petraea (Lobeliaceae). Mol. Ecol. 8: 775-789.

Castiglioni L and de Campos Bicudo HE (2005). Molecular characterization and relatedness of Haematobia irritans (horn fly) populations, by RAPD-PCR. Genetica 124: 11-21.

Castro U, Cardona C, Vera-Graziano J, Miles J, et al. (2007). Identificación morfológica y molecular de Prosapia simulans (Walker) (Hemiptera: Cercopidae), y selección y mecanismos de resistencia a este salivazo en híbridos de Brachiaria. Neotrop. Entomol. 36: 547-554.

de Oliveira CM, Lopes JR, Camargo LE, Fungaro MH, et al. (2007). Genetic diversity in populations of Dalbulus maidis (DeLong and Wolcott) (Hemiptera: Cicadellidae) from distant localities in Brazil assessed by RAPD-PCR markers. Environ. Entomol. 36: 204-212.

Ercan AG, Taskin M and Turgut K (2004). Analysis of genetic diversity in Turkish sesame (Sesamum indicum L.) populations using RAPD markers. Genet. Res. Crop Evol. 51: 599-607.

Excoffier L, Smouse PE and Quattro JM (1992). Analysis of molecular variance inferred from metric distances among DNA haplotypes: application to human mitochondrial DNA restriction data. Genetics 131: 479-491.

Ferreira ME and Grattapaglia D (1955). Introdução ao Uso de Marcadores Moleculares em Análise Genética. 2nd edn. EMBRAPA/CENARGEN, Brasília.

Hawkins BA and Lawton JH (1995). Latitudinal gradients in butterfly body sizes: is there a general pattern? Oecologia 102: 31-36.

Mikac KM and Clarke GM (2006). Tracing the geographic origin of the cosmopolitan parthenogenetic insect pest Liposcelis bostrychophila (Psocoptera: Liposcelididae). Bull. Entomol. Res. 96: 523-530.

Nei M and Li WH (1979). Mathematical model for studying genetic variation in terms of restriction endonucleases. Proc. Natl. Acad. Sci. U. S. A. 76: 5269-5273.

Oliveira RS, Nunes FMF, Campos APS, Vasconcelos SM, et al. (2004). Genetic divergence in Tetragonisca angustula Latreille, 1811 (Hymenoptera, Meliponinae, Trigonini) based on RAPD markers. Genet. Mol. Biol. 27: 181-186.

Parani M, Singh KN, Rangasamy S and Ramalingam RS (1997). Identification of Sesamum alatum x Sesamum indicum hybrid using protein, isozyme and RAPD markers. Indian J. Genet. Plant Breed. 57: 381-388.

Pérez T, Albornoz J and Dominguez A (1998). An evaluation of RAPD fragment reproducibility and nature. Mol. Ecol. 7: 1347-1357.

Semagn K (2002). Genetic relationships among ten encoded types as revealed by a combination of morphological, RAPD and AFLP markers. Hereditas 137: 149-156.

Skroch P and Nienhuis J (1995). Impact of scoring error and reproducibility RAPD data on RAPD based estimates of genetic distance. Theor. Appl. Genet. 91: 1086-1091.

Smith RJ, Hines A, Richmond S, Merrick M, et al. (2000). Altitudinal variation in body size and population density of Nicrophorus investigator (Coleoptera: Silphidae). Environ. Entomol. 29: 290-298.

Tauber JM, Tauber AC and Masaki S (1986). Insect Adaptation to Environmental Change. In: Seasonal Adaptations of Insects (Tauber JM, Tauber AC and Masaki S, eds.). Oxford University Press, New York, 7-37.

Waldschmidt AM, Barros EG and Campos LAO (2000). A molecular marker distinguishes the subspecies Melipona quadrifasciata quadrifasciata and Melipona quadrifasciata anthidioides (Hymenoptera: Apidae, Meliponinae). Genet. Mol. Biol. 23: 609-611.

Weising K, Nybom H, Wolff K and Meyer W (1995). DNA Fingerprinting in Plants and Fungi. CRC Press, Boca Ranton. 